\title{
$\mathrm{He}-\mathrm{Ne}$ レーザによるカオリンおよび底泥の光散乱特性*
}

\author{
高 坂 涁 夫** 高 橋 健 一*** \\ 松田良弘***二階堂清志****
}

\section{He-Ne Laser Scattering Characteristics of Kaolin and Sediment Suspension}

by

\author{
Ayao Takasaka, Kenichi Takahashi, Yoshihiro Matsuda \\ (Faculty of Engineering, Yamagata University, Yonezawa) \\ and Kiyoshi NIKAIDO \\ (Kurita Water Industries LTD., Tokyo)
}

The aim of this paper is to describe an apparatus for determining scattering characteristics of suspension by the dissymmetry method which enables the average particle size to be estimated quickly.

This dissymmetry method is based on the fact that the intensity of scattered light is not distributed symmetrically around the axis passing throught the particles in a direction perpendicular to the light beam, because the particle is not a point light-source. Rays scattered from different parts of the particle may give interference.

Therefore, it is possible to estimate the average particle size from the ratio of the intensities of scattered light at two angles, e.g. $Z_{45}$ at $45^{\circ}$ and $135^{\circ}$.

The dependence of the average particle size $D_{a v}(\mu \mathrm{m})$ by the photo-extinction method of kaolin minerals and sediment on the dissymmetry parameter $Z_{45}$ is given as follows:

$$
Z_{45}=-0.841 D_{a v}+8.363
$$

The dissymmetry method with a He-Ne gas laser as a light source is considered applicable to the estimation of the average particle size in the disposal process of factory wastes containing suspended particles, and to the control of particle size in the wastes as well as the quality control in the production process of factory.

(Received Feb. 5, 1982) キー・ワード : カオリン, 底泥, 光散乱, He-Ne ガスレーザ

\section{1 緒言}

微粒子群の懸濁液に光を照射すると, 入射光のある ものはあらゆる方向に散乱され，一部は吸収され，残 りが透過する. この際, 散乱光の強度や入射光の減少 が粒子径や濃度などの複雑な関数となることが知られ ている.

微粒子群の懸濁液を自然または遠心力沈降させ, 沈

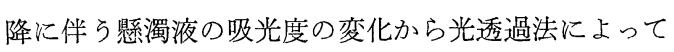
粒度分布を測定する理論および技術は，ほ汸確立され ている.しかし, 本法は測定に数分〜数十分かかり, プロセスでの粒度のオンライン測定の問題点となって (๖).

* 原稿受理 昭和57年 2 月 5 日

** 正会 員 山形大学工学部 米尺市域南

*** 山形大学工学部

**** 栗田工業(株)東京本社 東京都新宿区西新宿
一方, Mie 理論に基づく気相中の単分散粒子の散 乱光による粒径測定技術は, 近年かなりの進歩がみら れる。しかし，液相中の多分散系へ応用するまでには 至っていない.

また,コロイド領域下でブラウン運動する粒子群に 光を照射し，その散乱光の連続的変動を自動相関分光 法によって解析し, 平均粒子径として表示するCoulter Nano-Sizer (測定粒子径範囲 $0.004 \sim 0.3 \mu \mathrm{m}$ ), フラ ウンホーファ回折像を解析する Laser Granulomètre

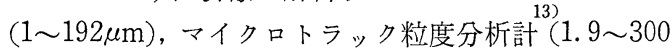
$\mu \mathrm{m})$ などが市販されている.

多くの微粉体は液相中で多分散粒子群となるため, その光散乱現象は複雑で未だ十分解明されていない，

本研究では, 光源として He-Ne ガスレーザを用い, 種々なるカオリン鉱物和よび底泥の光散乱特性を測定 し, その粒度や濃度などとの関連性を明らかにした。 
光散乱による測定は迅速に情報が得られるので，そ の解析法が確立できれば，将来懸濁液を使用する生産 プロセスや浮遊懸濁物を含む水処理プロセスへ応用可 能と思われる。

$$
2 \text { 試料 }
$$

実験に使用した試料は, Table I に示すように, カ オリン鉱物および底泥である．表中の試料の平均粒径 は，島津遠心沈降式粒度分布測定装置 CP-50 による 測定值である。なお，これらの試料は脱イオン水で任 意の濃度に調製して実験に使用した。

Table I. Sample of kaolin minerals and sediment.

\begin{tabular}{r|l|c}
\hline No & \multicolumn{1}{|c|}{ Name } & Dav $(\mu \mathrm{m})$ \\
\hline 1 & Hattor Kaolın & 1.0 \\
2 & Mexico Kaolın & 15 \\
3 & Nu clay & 13 \\
4 & USSR kaolın & 2.0 \\
5 & Ohta river sedıment & 35 \\
6 & Takamatu Harbour sediment & 3.6 \\
7 & Hiro bay sediment & 265 \\
8 & Hachinohe bay sedıment & 23 \\
9 & Biwa lake sediment (1) & 33 \\
10 & Biwa lake sediment (2) & 205 \\
11 & Biwa lake sediment (3) & 215 \\
\hline
\end{tabular}

\section{$3 \cdot 1$ 実験装置}

\section{3 実験装置および実験方法}

実験に使用した $\mathrm{He}-\mathrm{Ne}$ ガスレーザによる微粉体の 光散乱特性測定装置は試作したもので，その概略を Fig. 1 に示す. He-Ne ガスレーザ（ユニバーシテイ ラボ社製，モデル200，波長 $6323 \AA ， 0.6 \mathrm{mW，ビー}$ ム口径 $1.4 \mathrm{~mm}$ ) の光束は, スリット，ガラス製アン プル（内径 $20 \mathrm{~mm} \phi$, 高さ $75 \mathrm{~mm}$ ) 中の懸濁液を通 り，フォトセル（ミッミ電機製 2PK-63）に受けられ る. その, 最大分光感度を示す波長は約 $6000 \AA$ で,
$\mathrm{He}-\mathrm{Ne}$ ガスレーザの波長に近い。アンプルは, シン クロナスモータ $(1 \mathrm{rpm})$ の台上に乗せられており， フォトセルはアンプルセルと一緒に回転される。

懸溜液中の粒子群による散乱光強度は,フォトセル の電気抵抗変化として，ディジタル抵抗計（東芝 ST2240B）で測定し，ディジタルレコーダ（東芝 ST2260B）で記録する.

\section{$3 \cdot 2$ 実験方法}

アンプルに一定濃度のカオリンまたは底泥の䀣濁液 を入れる．懸濁液に $\mathrm{He}-\mathrm{Ne}$ ガスレーザを照射し，タ ーンテーブルを回転しながら，粒子群によって種々な る方向に散乱されるレーザ光の散乱強度を測定する (1 分間に約 300 回の測定々記録が可能である).

Fig. 2 は，測定の概念を示したものである．上述の ように, フォトセルは, ターンテーブルと一緒に動い て散乱角 $10 \sim 170^{\circ}$ の散乱光量を連続的に測定する.

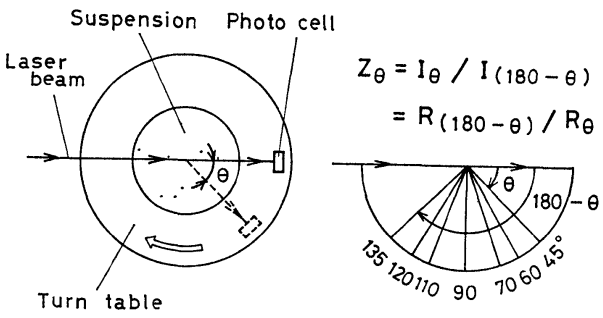

Fig. 2. Conception of the $Z_{\theta}$

測定結果は，後述（Fig.4 (a)〜 (c)) するように，グ ラフの横軸に散乱角度 [0 ${ }^{\circ}$, 縌軸にフォトセルの抵抗 $R[\mathrm{k} \Omega]$ として整理する.

また，入射光に対して回転角 $\theta=90^{\circ}$ を中とした 光散乱の非対称性を検討するため， $Z_{\theta}$ なる因子を導 入した。

$$
Z_{\theta}=I_{\theta} / I_{(180-\theta)}=R_{(180-\theta)} / R_{\theta}
$$

\section{4 実験結果および考察}

\section{$4 \cdot 1$ 懸濁液中のカオリン濃度と散乱光強度}

服部カオリン, メキシュカオリン, USSR カオリン,

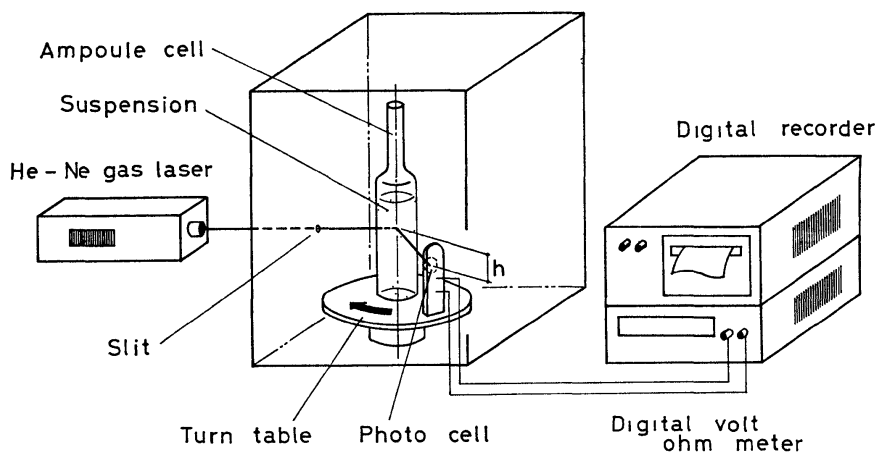

Fig. 1. Apparatus for determining scattering characteristic of suspension by the dissymmetry method. 


$$
\left(\times 10^{-2}\right)
$$

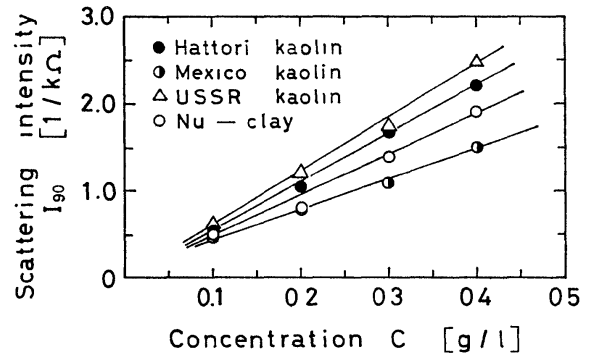

Fig. 3. Relation between scattering intensity and concentration of kaolin.

$\mathrm{Nu}$-Clay（米国産）について，散乱角 $90^{\circ}$ に抢いて䯚 濁液の濃度と散乱強度の関係を測定した。

Fig. 3 に示すように，いずれの試料も懸濁液中の粒 子群の濃度が高くなるほど，散乱強度が増加すること が明らかである。

\section{$4 \cdot 2$ カオリン懸濁液の光散乱特性}

Table II に示す粒度分布をるつ ST カオリン（国 産）の懸濁液（濃度 $0.163 ， 0.244 ， 0.488 \mathrm{~g} / l$ ) を調製 し，Fig. 1 亿示したレーザ光束の垂直方向に散乱され る位置 $h=0 \sim 2[\mathrm{~cm}]$ の範囲内で, 散乱角の变化に伴 らフォトセルの抵抗 $[\mathrm{k} \Omega]$ 变化を測定した。 その結 果の例を Fig. 4 (a) ( c) に示す.

Table II. Particle size distribution of ST kaolin.

\begin{tabular}{c|c}
\hline Particle size $(\mu \mathrm{m})$ & Cumulative \% over size \\
\hline 20 & 0 \\
15 & 20.7 \\
10 & 33.7 \\
8 & 42.6 \\
6 & 52.5 \\
5 & 54.9 \\
4 & 63.8 \\
3 & 70.8 \\
2 & 814 \\
\hline
\end{tabular}

図から，懸濁液中の粒子群の濃度が一定な場合は， 散乱光の強度は, $h=0[\mathrm{~cm}]$ のところが一番強く, $h$ が大きくなる棌ど弱くなることがわかる，また，懸濁 粒子群によるレーザの散乱は, 粒子濃度が大きくなる ほど強くなり，粒子濃度が小さくなると散乱角 100〜 $120^{\circ}$ 付近で非常に弱くなることがわかる.

これら類似の現象は，他のカォリン繋濁液について も文られる。（図省略）

\section{$4 \cdot 3 \quad Z_{\theta}$ と懸濁粒子群平均粒径の関係}

本実験恃すべて散乱角 $\theta=10 \sim 170^{\circ}$ について行い, $h=0$ において散乱角 $\theta=90^{\circ}$ を中心とした光散乱の 非対称性が，贃濁粒子群の平均粒径泪関があるか否 かを検討した。な特，測定時の試料濃度範囲 $(0.4 \mathrm{~g} / l$ 以下）では， $Z_{\theta}$ 洁活涪一定值となる。

Fig.5〜 7は, Table I のカオリン拈よび底泥飞対 して, $Z_{45}, Z_{60}, Z_{70}$ と平均粒径の 関係を示した結果 である。こ犰から最小自乗法によって $Z_{\theta}$ と $D_{a v}[\mu \mathrm{m}]$ の関係を求めると

$$
Z_{45}=-0.841 D_{a v}+8.363
$$

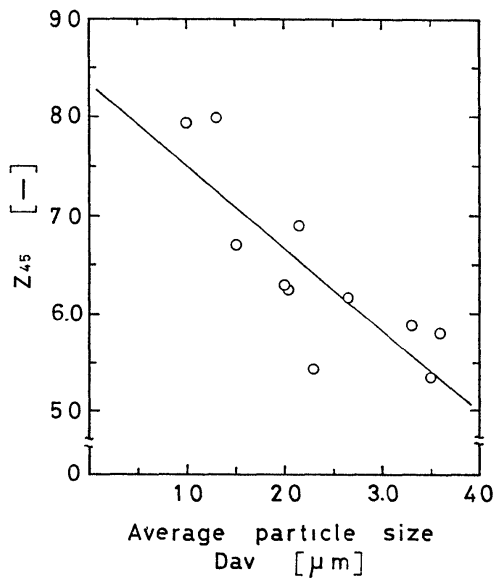

Fig. 5. Dependence of average particle size on dissymmetry parameter $Z_{45}$ for various suspension.

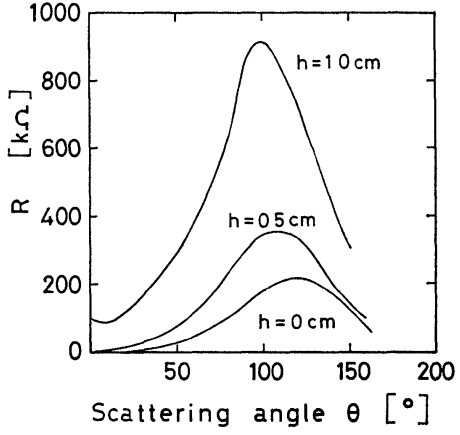

(a) Concentration $0.163 \mathrm{~g} / \mathrm{l}$

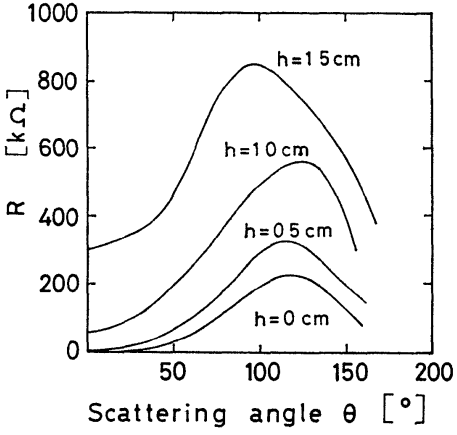

(b) Concentration $0.244 \mathrm{~g} / l$

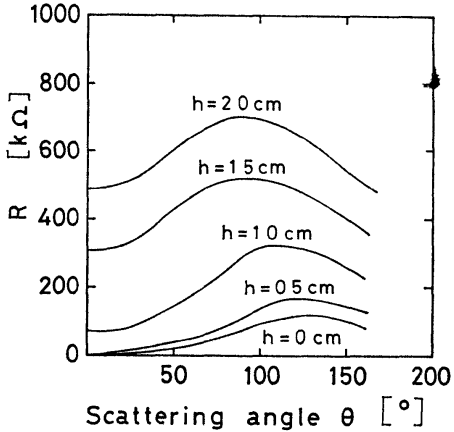

(c) Concentration $0488 \mathrm{~g} / \mathrm{l}$

Fig. 4. Light scattering diagram of kaolin suspension. 


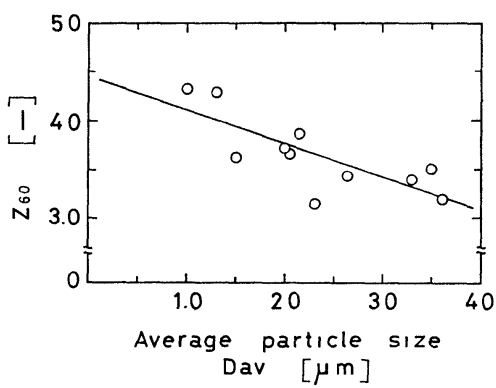

Fig. 6. Dependence of average particle size on dissymmetry parameter $Z_{60}$ for various suspension.

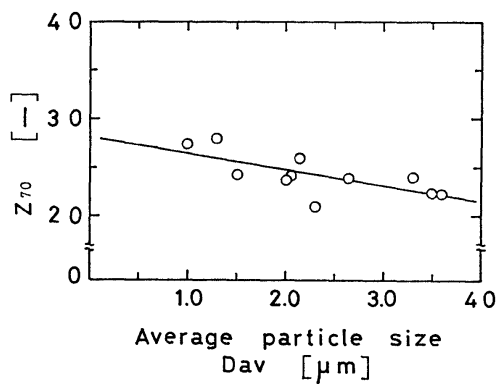

Fig. 7. Dependence of average particle size on dissymmetry parameter $Z_{70}$ for various suspension.

$$
\begin{aligned}
& Z_{60}=-0.339 D_{a v}+4.453 \\
& Z_{70}=-0.169 D_{a v}+2.817
\end{aligned}
$$

なる式が得られた（相関係数は， $Z_{45}$ のとき， -0.824 , $Z_{60}$ のとき $-0.774, Z_{70}$ のとき -0.701 である.)

$Z_{\theta}$ と $D_{a v}$ の相関はあまり良いとは2六市ない。これ は, 試料が球状ではなく, 粒度分布を有しており, ま た底泥は異種物質を含む混合物であるなどの理由によ るものと考えられる。

しかし実験の範囲内では, 平均粒径が大きくなるほ ど $Z_{\theta}$ が小さくなる相関が成立つことが判明した。ま た， $Z_{\theta}$ の平均粒径依存性は，(1)式の $\theta=45$ のとき, 相関係数の絶対值が大きい.

\section{5 結言}

$\mathrm{He}-\mathrm{Ne}$ ガスレーザを光源として, 工業用粉体であ るカオリンおよび環境上問題となっている底泥の懸濁 液の光散乱特性について研究した.

光散乱の非対称性をあらわす因子 $Z_{\theta}$ (Fig. 2 および (1)式参照）と光透過法で測定した懸濁粒子群の平均粒
径 $D_{a v}[\mu \mathrm{m}]$ の間には，一定の相関があることが判明 した.このうち， $Z_{45}$ を用いることにより，懸濁粒子 群の平均粒径を推定できる.

本研究で取扱ったような多分散系の懸濁液の光散乱 特性については, 現在理論的, 技術的に解明されてい ない多くの問題点がある，現状では，筆者らが先に研 究した光透過法による粒度分布測定法が有利のように 思われるが，測定時間がかかるためソ゚ロセスとのオン ライン化の際の問題点になっている.

この点, 本研究の光散乱法は, 微粉体の䀣濁液に $\mathrm{He}-\mathrm{Ne}$ カススレザを照射して扣き，光束に対して $45^{\circ}$ および $135^{\circ}$ に散乱される光の強度比を測定すること により平均粒径に関する情報が迅速に得られる.

したがって, 従来の自然, 遠心沈降法によらない才 ンライン粒度測定法として発展させることにより，粘 土鉱物の精製工程, 排水中の微粒子懸濁物 (SS) など の迅速な平均粒径推定法として利用できる可能性を含 んでいる.

（昭和56年10月28日 第19回粉体に関する討論会にて講演）

\section{参 考 文 献}

1) オァー, ダァラァバァル共著, 牟田明徳, 角田光雄共訳, “粉体の測定” p. 75 (1968) 産業図書

2）高坂柁夫, 篠崎平馬, 遠田保彦, 井上達也, 遠藤二男, 材料, 13, 315 (1964).

3) 高坂彬夫, 粉体工学, 2, 1225 (1965).

4) 高坂彬夫, 安部保志, 第11回粘土科学討論会要旨集, 28 (1967).

5) 高坂彬夫, 安部保志, 材料, 17, 570 (1968).

6）高坂彬夫, 姜 義清, 材料, 18, 526 (1969).

7) 高坂彬夫, 大門芳雄, 化学工学協会第37年会要旨集, II, 183 (1972).

8）高坂彬夫, 松田良弘, 材料, 24, 600 (1975).

9）高坂樹夫, 蟹汇 守, 松田良弘, 第25回記念粘土科学討 論会要旨集, 39 (1981).

10）粉体工学研究会, “粒度測定技術” p. 18 (1975) 日刊工 業新聞社

11）日科機, “Coulter Nano-Sizer”カタログ (1981).

12) Compagnie Industrielle des Lasers, "Granulomètre A Laser modèle 715” カタログ (1979).

13）日機装, “マイクロトラック粒度分析計”カタログ(1978).

14）環境技術研究会 “下水・廃水・污泥処理ガイドブック” p. 823 (1979) 理工新社 